\title{
Yogic-humming: A Respiratory Defense Booster for COVID Times
}

\author{
Prashanth Panta ${ }^{1}$, Sravya Reddy Dhopathi ${ }^{2}$, Archana Andhavarapu ${ }^{3}$, Shankargouda Patil ${ }^{4}$ \\ The Journal of Contemporary Dental Practice (2021): 10.5005/jp-journals-10024-3134
}

The traditional Indian healthcare system of Yoga contains a wealth of health-promotional practices-some of which are based on "humming." "Humming" is produced when a wordless sound is forced to exit through the nose while keeping the mouth either fully closed or nearly closed; it is a low, prolonged, and buzzing sound. In humming practices like "Bhramari pranayama" (normal inhalation followed by lengthened exhalation + beelike humming), there is a full-mouth closure, ${ }^{1}$ and in practices like "OM chanting" (normal inhalation followed by lengthened exhalation +OM humming), there is a near-closure. Besides these, other mantra-oriented practices also generate a similar humming effect.

It is not known why humming was integrated into the Yogic system. The breakthrough work by Weitzberg and Lundberg showed that "humming" causes "Nitric oxide" (NO) release from the paranasal sinus. ${ }^{2}$ This effect results from humming-induced air oscillation that increases the air exchange between the paranasal sinuses and nasal cavity. Their work showed that a significantly high NO output (15-fold) occurs during humming compared to quiet exhalation. $^{2}$

There is also evidence that NO stimulates ciliary action. Cilia establish primary contact with respiratory pathogens, ${ }^{3}$ and many (including severe acute respiratory syndrome coronavirus 2 (SARSCoV-2)) target the ciliary system during disease progression. ${ }^{4,5}$ NO was shown to improve the planar polarity and the ciliary beat frequency, which are essential to retaining the unidirectional mucous flow across the mucociliary epithelium, which enables mucous clearance., ${ }^{4,5}$

NO also has a broad-spectrum antiviral effect against influenza-, rhino-, and coronaviruses like severe acute respiratory syndrome coronavirus (SARS-CoV) and SARS-CoV-2. ${ }^{6,7}$ There is also an intriguing case report in which prolonged humming for only a short period caused quick resolution of "rhinosinusitis," a condition of predominant fungal etiology. ${ }^{8}$ Another group studied the effect of Bhramari as an adjunct to conventional therapy in managing chronic rhinosinusitis on a larger sample population; ${ }^{9}$ their data indicate better outcomes when Bhramari was combined with conventional therapy (meaning it has therapeutic potential). It is logical to consider "rhinosinusitis" as a model to understand the benefit of humming on fungal infections. NO was also shown to exhibit a widespread inhibitory effect on fungal strains like Aspergillus niger which are also pathogens associated with coronavirus disease-2019 (COVID-19). ${ }^{10,11}$ It is noteworthy that because of the broad spectrum antifungal nature of NO, compounds releasing it have been utilized to treat fungal infections. ${ }^{12,13}$ Since there is a surge in COVID-associated mucormycosis cases, it is crucial
${ }^{1}$ Department of Oral Medicine and Radiology, MNR Dental College and Hospital, Sangareddy, Telangana, India

${ }^{2}$ Department of Periodontics, MNR Dental College and Hospital, Sangareddy, Telangana, India

${ }^{3}$ Department of Respiratory Medicine, Malla Reddy Medical College for Women, Hyderabad, Telangana, India

${ }^{4}$ Department of Maxillofacial Surgery and Diagnostic Sciences, Division of Oral Pathology, College of Dentistry, Jazan University, Jazan, Saudi Arabia

Corresponding Author: Prashanth Panta, Department of Oral Medicine and Radiology, MNR Dental College and Hospital, Sangareddy, Telangana, India, Phone +91 9701806830, e-mail: maithreya.prashanth @gmail.com

How to cite this article: Panta P, Dhopathi SR, Andhavarapu A, et al. Yogic-humming: A Respiratory Defense Booster for COVID Times. J Contemp Dent Pract 2021;22(7):721-723.

Source of support: Nil

Conflict of interest: None

to revisit if NO may confer protection against such infections. There is evidence of NO's inhibitory role on spore germination of Rhizopus spp. (causative organism of mucormycosis). ${ }^{14}$ NO (released following humming sessions) may help combat COVIDassociated fungal pathosis.

NO could potentially improve macrophage and neutrophil activity. ${ }^{14,15}$ Neutrophils inhibit fungi through a series of mechanisms such as phagocytosis, oxidative burst, and neutrophil extracellular traps. ${ }^{16} \mathrm{NO}$ also has anti-inflammatory properties. It inhibits the proliferation of immune cells and inhibits cytokine production across a range of white blood cells (lymphocytes, eosinophils, monocytes), thus protecting from severe inflammatory events (like cytokine storm) and reducing associated tissue injury. ${ }^{17}$ $\mathrm{NO}$ also exerts strong bronchodilatory and bronchoprotective effects, mainly caused via smooth muscle relaxation. ${ }^{17}$ The antithrombolytic effect of NO is mediated through inhibition of platelet adhesion and aggregation, inhibition of smooth muscle cell proliferation, and vasodilation. ${ }^{18,19}$ There is literature on the use of NO-releasing drugs as effective antithrombotic agents. ${ }^{19}$ Such is the antithrombotic potential of NO. Since there is compelling evidence on COVID-19 as a thromboembolic disease, strategies increasing the NO pool could be helpful.

The multiple mechanisms triggered by NO may confer protection and serve a therapeutic role in coronavirus disease 2019 (COVID-19) (Flowchart 1). When NO is being adopted as a potential rescue therapy against COVID-19 and when intranasal NO sprays are

(c) Jaypee Brothers Medical Publishers. 2021 Open Access This article is distributed under the terms of the Creative Commons Attribution 4.0 International License (https://creativecommons.org/licenses/by-nc/4.0/), which permits unrestricted use, distribution, and non-commercial reproduction in any medium, provided you give appropriate credit to the original author(s) and the source, provide a link to the Creative Commons license, and indicate if changes were made. The Creative Commons Public Domain Dedication waiver (http://creativecommons.org/publicdomain/zero/1.0/) applies to the data made available in this article, unless otherwise stated. 
Flowchart 1: Yogic-humming practices cause nitric oxide release that triggers a broad set of mechanisms including antimicrobial (antiviral, antifungal) and anti-inflammatory activity, improved ciliary function (that increases the mucosal clearance), and vasodilation and bronchodilation (that improve oxygenation), and antithrombotic activity (that reduces thrombo-embolic events). They may play a constructive role in preventing SARS-CoV-2 infection and/or mitigating COVID-19 progression

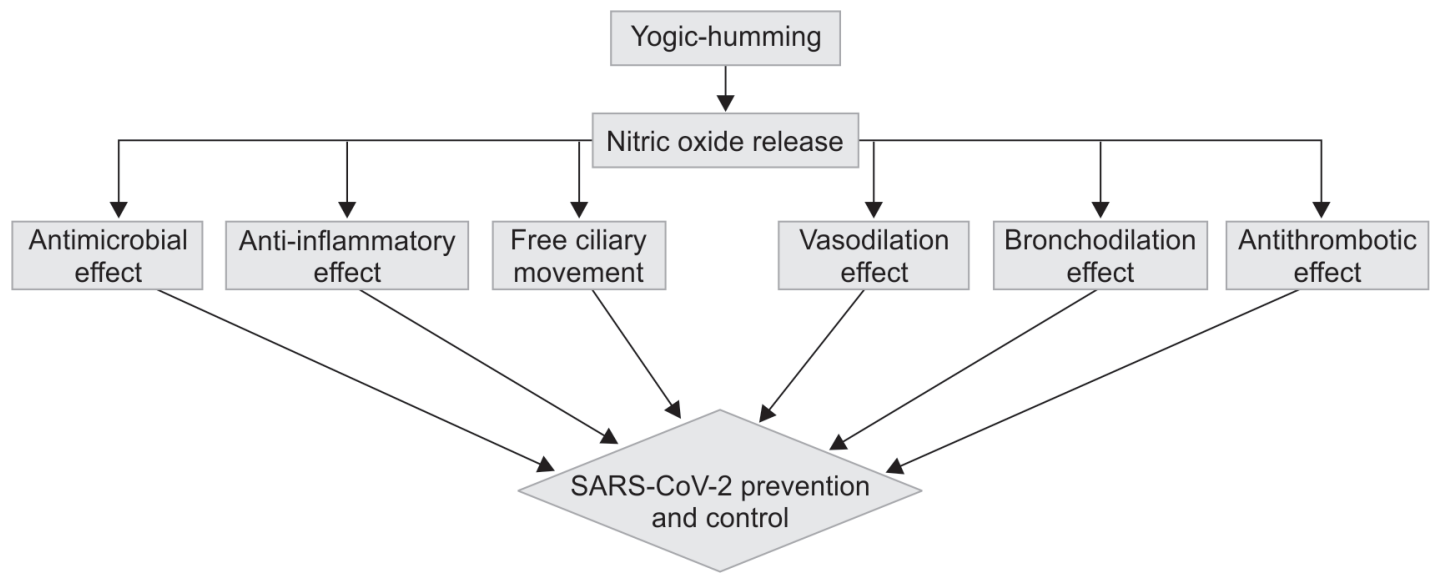

bolstered for commercial use, ${ }^{17,20,21}$ why not consider the relatively simple humming practices to release NO naturally?

NO participates in a wide range of cellular chemistry ranging from oxidation, antioxidant, nitrosation, and nitration reactions. ${ }^{22}$ Hence, it is bound to possess multiple roles, and it is vital to recognize the complex dynamics involved. COVID-19 patients showed a decreased blood NO levels compared to non-COVID patients; on the contrary, patients who died from COVID had more NO than those who survived. ${ }^{23}$ Therefore, we must understand NO's complex role in the context of COVID-19 progression. Decreased NO bioavailability and decreased endothelial NO have been linked with severe COVID-19, and few investigators mention that COVID-19 could itself be a NO-related disease process. ${ }^{24} \mathrm{NO}$ can be acquired through different pathways such as intracellular source (following viral infection and associated inflammation) or through catalytic generation (through enzymes and enzyme mimics) or via the direct delivery of $\mathrm{NO}$ and its donors; each of these sources determine the final NO pool. ${ }^{6}$ Since NO at higher levels can have tissue-damaging effects (due to oxidative stress), it is vital to consider the endogenous sources (like humming) than exclusively exogenous sources.

Unhealthy habits (e.g., smoking, mouth breathing) can also negatively impact respiratory NO levels, and adopting the humming practices could boost the respiratory defense via the restoration and upregulation of NO levels. ${ }^{25,26}$ Such practices may be considered complementary measures and need to be integrated into daily Yoga. Besides their primary preventive role against SARS-CoV-2 infection (due to the inhibition of viral replication), ${ }^{7}$ they may also benefit non-hospitalized COVID-19 patients in home-quarantine settings. NO-building practices warrant deeper scientific inquiry through well-designed experiments.

We must give greater attention to the safe, no-cost, and homebased risk reduction alternatives. Following a positive lifestyle (mainly composed of Yoga) is especially vital during COVID times as it stimulates health via multiple biochemical pathways (NO and non-NO pathways). However, these measures are underrated by the scientific community, and it therefore necessary to promote research in this direction.

\section{References}

1. Taneja MK. Modified Bhramari pranayama in Covid 19 infection. Indian J Otolaryngol Head Neck Surg 2020;72(3):395-397. DOI: 10.1007/ s12070-020-01883-0.

2. Weitzberg $E$, Lundberg JO. Humming greatly increases nasal nitric oxide. Am J Respir Crit Care Med 2002;166(2):144-145. DOI: 10.1164/ rccm.200202-138BC

3. Kuek LE, Lee RJ. First contact: the role of respiratory cilia in hostpathogen interactions in the airways. Am J Physiol Lung Cell Mol Physiol 2020;319(4):L603-L619. DOI: 10.1152/ajplung.00283.2020.

4. Jain B, Rubinstein I, Robbins RA, et al. Modulation of airway epithelial cell ciliary beat frequency by nitric oxide. Biochem Biophys Res Commun 1993;191(1):83-88. DOI: 10.1006/bbrc.1993.1187.

5. Mikhailik A, Michurina TV, Dikranian K, et al. nNOS regulates ciliated cell polarity, ciliary beat frequency, and directional flow in mouse trachea. Life Sci Alliance 2021;4(5):e202000981. DOI: 10.26508/ Isa.202000981.

6. Lisi F, Zelikin AN, Chandrawati R. Nitric oxide to fight viral infections. Adv Sci (Weinh). 2021;8(7):2003895. DOI: 10.1002/advs.202003895.

7. Akaberi $D$, Krambrich J, Ling J, et al. Mitigation of the replication of SARS-CoV-2 by nitric oxide in vitro. Redox Biol 2020;37:101734. DOI: 10.1016/j.redox.2020.101734.

8. Eby GA. Strong humming for one hour daily to terminate chronic rhinosinusitis in four days: a case report and hypothesis for action by stimulation of endogenous nasal nitric oxide production. Med Hypotheses 2006;66(4):851-854. DOI: 10.1016/j.mehy.2005.11.035.

9. Abishek K, Bakshi SS, Bhavanani AB. The efficacy of yogic breathing exercise bhramari pranayama in relieving symptoms of chronic rhinosinusitis. Int J Yoga 2019;12(2):120-123. DOI: 10.4103/ ijoy.IJOY_32_18.

10. Lazar EE, Wills RB, Ho BT, et al. Antifungal effect of gaseous nitric oxide on mycelium growth, sporulation and spore germination of the postharvest horticulture pathogens, Aspergillus niger, Monilinia fructicola and Penicillium italicum. Lett Appl Microbiol 2008;46:688692. DOI: 10.1111/j.1472-765X.2008.02373.x.

11. Trovato L, Calvo M, Migliorisi G, et al. Fatal VAP-related pulmonary aspergillosis by Aspergillus niger in a positive COVID-19 patient. Respir Med Case Rep 2021;32:101367. DOI: 10.1016/j.rmcr.2021.101367.

12. Stasko N, McHale K, Hollenbach SJ, et al. Nitric oxide-releasing macromolecule exhibits broad-spectrum antifungal activity and utility as a topical treatment for superficial fungal infections. Antimicrob Agents Chemother 2018;62(7):e01026-17. DOI: 10.1128/ AAC.01026-17. 
13. Navarathna DH, Lionakis MS, Roberts DD. Endothelial nitric oxide synthase limits host immunity to control disseminated Candida albicans infections in mice. PLoS One 2019;14(10):e0223919. DOI: 10.1371/journal.pone.0223919.

14. Jorens PG, Boelaert JR, Halloy V, et al. Human and rat macrophages mediate fungistatic activity against Rhizopus species differently: in vitro and ex vivo studies. Infect Immun 1995;63:4489-4494. DOI: 10.1128/IAI.63.11.4489-4494.1995.

15. Nolan S, Dixon R, Norman $K$, et al. Nitric oxide regulates neutrophil migration through microparticle formation. Am J Pathol 2008;172(1):265-273. DOI: 10.2353/ajpath.2008.070069.

16. Urban CF, Nett JE. Neutrophil extracellular traps in fungal infection. Semin Cell Dev Biol 2019;89:47-57. DOI: 10.1016/j.semcdb.2018. 03.020 .

17. Fang W, Jiang J, Su L, et al. The role of NO in COVID-19 and potential therapeutic strategies. Free Radic Biol Med 2021;163:153-162. DOI: 10.1016/j.freeradbiomed.2020.12.008.

18. Gresele P, Momi S, Guglielmini G. Nitric oxide-enhancing or -releasing agents as antithrombotic drugs. Biochem Pharmacol 2019;166:300312. DOI: 10.1016/j.bcp.2019.05.030.

19. Emerson M, Momi S, Paul W, et al. Endogenous nitric oxide acts as a natural antithrombotic agent in vivo by inhibiting platelet aggregation in the pulmonary vasculature. Thromb Haemost 1999;81:961-966. DOI: 10.1055/S-0037-1614607.
20. Alvarez RA, Berra L, Gladwin MT. Home nitric oxide therapy for COVID-19. Am J Respir Crit Care Med 2020;202(1):16-20. DOI: 10.1164/ rccm.202005-1906ED.

21. Safaee Fakhr B, Wiegand SB, Pinciroli R, et al. High concentrations of nitric oxide inhalation therapy in pregnant patients with severe coronavirus disease 2019 (COVID-19). Obstet Gynecol 2020;136(6):1109-1113. DOI: 10.1097/AOG.0000000000004128.

22. Espey MG, Miranda KM, Thomas DD, et al. A chemical perspective on the interplay between NO, reactive oxygen species, and reactive nitrogen oxide species. Ann N Y Acad Sci 2002;962:195-206. DOI: 10.1111/j.1749-6632.2002.tb04068.x.

23. Dominic $P, A$ hmad J, Bhandari $R$, et al. Decreased availability of nitric oxide and hydrogen sulfide is a hallmark of COVID-19. Redox Biol 2021;43:101982. DOI: 10.1016/j.redox.2021.101982.

24. Ozdemir B, Yazici A. Could the decrease in the endothelial nitric oxide (NO) production and NO bioavailability be the crucial cause of COVID-19 related deaths? Med Hypotheses 2020;144:109970. DOI: 10.1016/j.mehy.2020.109970.

25. Yates $\mathrm{DH}$, Breen $\mathrm{H}$, Thomas PS. Passive smoke inhalation decreases exhaled nitric oxide in normal subjects. Am J Respir Crit Care Med 2001;164(6):1043-1046. DOI: 10.1164/ajrccm.164.6.2005043.

26. Martel J, Ko YF, Young JD, et al. Could nasal nitric oxide help to mitigate the severity of COVID-19? Microbes Infect 2020;22(4-5):168-171. DOI: 10.1016/j.micinf.2020.05.002. 